\title{
COMMUNICATION
}

Cite this: DOI: 10.1039/x0xx00000x

\section{Aqueous Nile blue: A simple, versatile and safe reagent for the detection of latent fingermarks}

\author{
Amanda A. Frick ${ }^{a}$, Francesco Busetti ${ }^{a}$, Andrew Cross $^{b}$ and Simon W. Lewis ${ }^{a}$
}

Received 00th January 2012,

Accepted 00th January 2012

DOI: $10.1039 / \times 0 \times x 00000 x$

www.rsc.org/

Nile blue $A$ in aqueous solution undergoes spontaneous hydrolysis to the photoluminescent compound Nile red. This reagent provides a simple and safe approach to the detection of latent fingermarks on porous and non-porous surfaces.

The detection of latent (invisible) fingermarks is highly significant in criminal investigations as a means of establishing connections between individuals, objects and locations. A variety of novel approaches to fingermark detection have been developed in recent years, in an effort to improve the overall sensitivity of the fingermark detection process. ${ }^{1-6}$

Detection of latent fingermarks on porous surfaces, such as paper, can be achieved using treatments that target compounds such as amino acids or lipids, that are derived from skin secretions. ${ }^{1,7}$ Commonly used amino acid-sensitive reagents, such as ninhydrin (2,2-dihydroxy-1,3-indanedione), 1,8diazafluoren-9-one (DFO) and 1,2-indanedione, are not suitable for items which have been wetted or exposed to high humidity, due to the solubility of amino acids in water. ${ }^{8,9}$ Detection of the water-insoluble fraction of latent fingermarks may be carried out with the silver nitrate-based reagent physical developer, or the lipophilic dye Oil Red O (1-([4-(xylylazo)xylyl]azo)-2naphthol). ${ }^{6},{ }^{10}$ Oil Red $\mathrm{O}$ is ineffective at developing fingermarks on dark or patterned substrates, as the colours conferred upon fingermarks do not provide sufficient contrast. In a similar fashion, physical developer requires additional processing when used on such substrates ${ }^{11-13}$.

Recently the use of Nile red (9-diethylamino-5Hbenzo $[\alpha]$ phenoxazine-5-one) has been reported as an approach to the detection of recently deposited fingermarks on porous substrates that have been wetted. This treatment imparts both colour and photoluminescence to lipid-rich fingermarks, allowing their detection on dark and/or patterned surfaces. ${ }^{14}$ However, as the operational use of this reagent would be performed by non-scientifically trained personnel, there are concerns regarding the toxicity of the organic solvent required (methanol) due to the poor solubility of Nile red in aqueous solution. ${ }^{15}$ There is a general move away from using methanol and other toxic solvents in such situations.

Nile blue A (benzo[a]phenoxazin-7-ium,5-amino-9(diethylamino)-,sulfate (2:1)), commonly referred to as Nile bluet, is a basic phenoxazine dye employed in histology. ${ }^{16-18}$ When prepared in aqueous solution, Nile blue A stains acidic components, such as phospholipids and nucleic and fatty acids, a dark blue colour, while neutral lipids, namely triglycerides, are stained pink or red. ${ }^{16,17,19}$ Nile red is the corresponding phenoxazone of Nile blue A, and can be synthesised by refluxing Nile blue $\mathrm{A}$ in dilute sulfuric acid. ${ }^{17,} 18,20$ The spontaneous hydrolysis of Nile blue A also occurs in the aqueous Nile blue staining reagent (Scheme 1). ${ }^{20-22}$ It is the presence of these two dyes in the one solution that gives Nile blue its dual staining capabilities: Nile blue A forms a salt linkage with acidic moieties, while Nile red dissolves preferentially into neutral lipids. ${ }^{17,19}$ It is accepted that the Nile red component is responsible for the photoluminescence emitted by tissues stained with Nile blue..$^{20,22-24}$ 


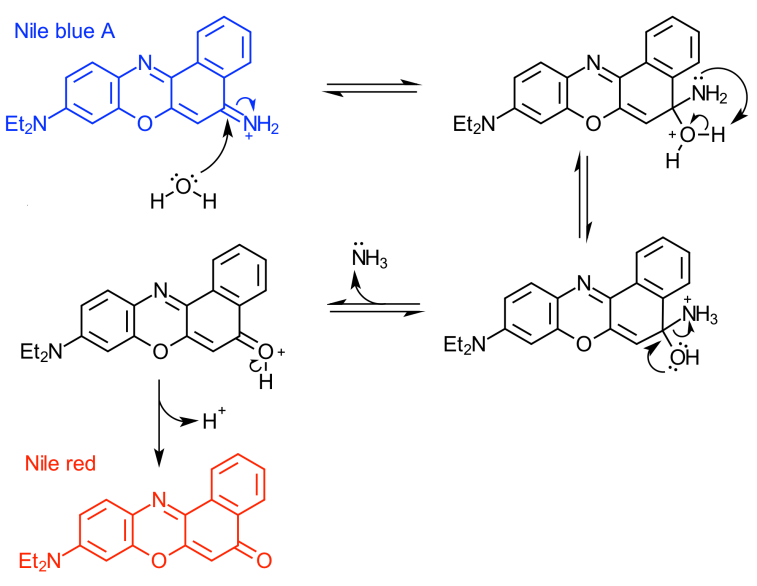

Scheme 1 Proposed reaction pathway for the spontaneous hydrolysis of Nile Blue $A$ to Nile Red in aqueous solution.

Nile red is present in the Nile blue histological stain in only trace amounts, but this is sufficient to provide colouration and photoluminescence in stained tissue sections. ${ }^{24,}{ }^{25}$ Nile blue A has previously been investigated in a forensic context as a powder or in alcoholic solution, for the detection of latent fingermarks ${ }^{26}$, including as a post-treatment stain for cyanoacrylate fuming of latent fingermarks ${ }^{27}$, and for the detection of latent lip prints. ${ }^{28}$ Here we propose an aqueous Nile blue solution as a treatment for the detection of latent fingermarks that overcomes the issue of using an organic solvent for Nile red for latent fingermark development, while providing a second development reagent in Nile blue A itself.

Latent fingermarks were collected on white copy paper from five donors. For these preliminary experiments, donors were asked to rub their fingers on their face or scalp immediately prior to fingermark deposition in order to 'charge' fingermarks with sebaceous lipids. Preparation of the Nile blue reagent was based on the method described by Cain. ${ }^{16}$ Nile blue A (5 mg; Aldrich; Sigma-Aldrich) was dissolved in deionised water $(100 \mathrm{~mL})$. The samples were immersed in the Nile blue solution for 20 minutes, before being briefly rinsed in deionised water. Samples were then blotted and left to dry on paper towels at ambient temperature. Both fresh and 24 hour old fingermarks were developed. As shown in Figure 1 and also in electronic supplementary information Figure S1, fingermarks on porous substrates treated with Nile blue appeared as very pale blue-purple impressions on a blue background, although frequently fingermarks were not visible under white light. Strong photoluminescence was exhibited under illumination from a forensic light source (Polilight ${ }^{\circledR}$ PL500, Rofin, Australia), with an excitation wavelength of $505 \mathrm{~nm}$ and viewed through an orange camera filter attachment $(550 \mathrm{~nm}$ barrier filter). The excitation and barrier filter wavelengths are similar to those used to examine fingermarks treated with Nile red. ${ }^{14}$ Additional fingermarks on paper were split and the resulting halves treated with Nile Blue and with Nile Red (prepared as described in Braasch et al. ${ }^{14}$ )
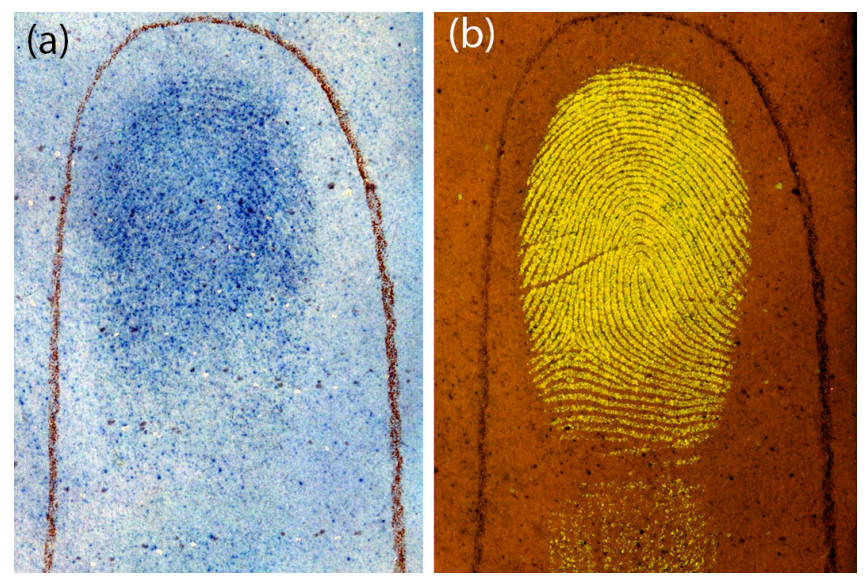

Figure 1 Latent fingermark on white copy paper treated with Nile blue, photographed using a Nikon D300 camera a) under white light (aperture f/8, shutter speed $1 / 20 \mathrm{~s}$ ) and b) photoluminescence mode (excitation with a Polilight PL 500 at $505 \mathrm{~nm}$ excitation and viewed through a $550 \mathrm{~nm}$ barrier filter, aperture $\mathrm{f} / 8$, shutter speed $2.0 \mathrm{~s}$ ).

The Nile Blue treated marks consistently gave better contrast, as those treated with Nile Red were effected by a higher level of background luminescence (Figure S1). It should be noted however that further studies are required with a wider range donors and substrates to establish the comparative performance of these two methods.

$10 \mu \mathrm{L}$ aliquots of 1:1 linseed oil in hexane (Mallinckrodt Chemicals) were pipetted onto white copy paper, dried, and treated with Nile blue. These linseed oil spots all demonstrated strong photoluminescence, indicating that Nile red is present, as Nile blue A does not interact with triglycerides. Fluorescence spectra of fingermarks treated with Nile blue compared very closely with those treated with an organic extract of the aqueous Nile Blue solution, giving an emission maximum at approximately $560 \mathrm{~nm}$ with excitation at $490 \mathrm{~nm}$ (see electronic supplementary information Figure S2). This is consistent with the viewing conditions required for fingermarks treated with Nile red. ${ }^{14,15}$

While Nile red is known to dissolve into neutral lipids, it is unclear what exact fingermark compounds are targeted by this reagent, as the linseed oil spots treated with Nile blue produced an emission maximum of $590 \mathrm{~nm}$ when excited at $490 \mathrm{~nm}$. The photoluminescence emission and excitation maxima of Nile red are solvent-dependant, so it is possible that the compositional differences between linseed oil (triglycerides) and latent fingermark residue are responsible for this shift. ${ }^{29}, 30$ High resolution mass spectra (HRMS) of an organic extract of the Nile blue reagent and a standard of Nile red provides further evidence that Nile red is present in the aqueous solution (see electronic supplementary material, Figure S2 and Table S2). Collision induced dissociation experiments confirmed the identity of Nile red in the sample extract by returning 4 characteristic fragments with the same accurate mass and similar relative abundance respect to those obtained from a standard solution, further confirming the presence of Nile red in the sample extract. 

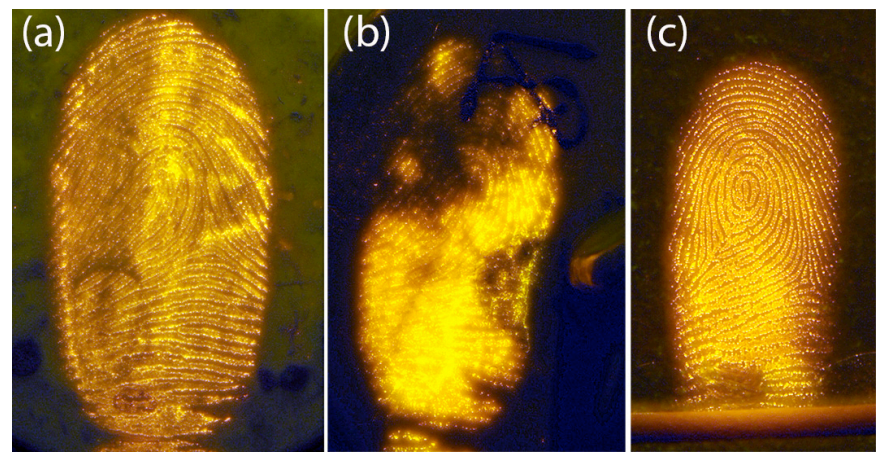

Figure 2 Latent fingermarks treated with Nile blue on a) plastic lid; b) ceramic crucible lid; and c) glass microscope slide. Photographed using a Nikon D300 camera in photoluminescence mode (excitation with a Polilight PL 500 at $505 \mathrm{~nm}$ excitation and viewed through a $550 \mathrm{~nm}$ barrier filter, aperture $\mathrm{f} / 8$, shutter speed $1 / 10 \mathrm{~s})$
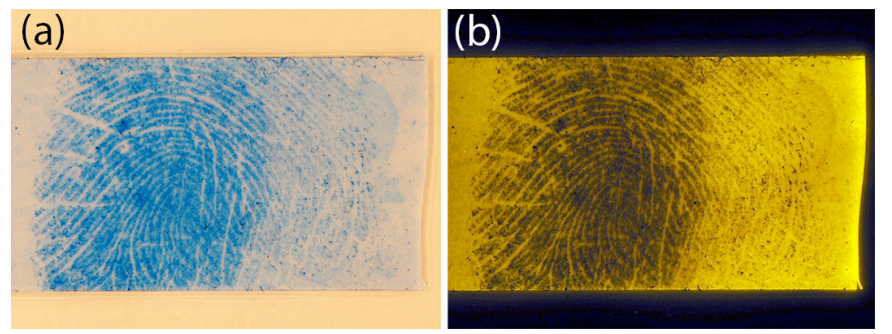

Figure 3 Latent fingermark on adhesive side of white electrical tape treated with Nile blue. Photographed using a Nikon D300 camera a) under white light (aperture $\mathrm{f} / 8$, shutter speed $1 / 20 \mathrm{~s}$ ) and b) photoluminescence mode (excitation with a Polilight PL 500 at $505 \mathrm{~nm}$ excitation and viewed through a $550 \mathrm{~nm}$ barrier filter, aperture $\mathrm{f} / 8$, shutter speed $1 / 20 \mathrm{~s}$ ).

In addition to the ability to visualise latent fingermarks on wetted paper surfaces, Nile blue was also found to develop latent fingermarks deposited on glossy, non-porous surfaces (Figure 2) and the adhesive side of electrical tapes (Figure 3). The visualisation of latent fingermarks on non-porous surfaces occurred in much the same manner as with porous surfaces. The mode of detection for fingermarks on adhesive surfaces appears to be significantly different, as fingermarks deposited on electrical tape appeared as blue, non-photoluminescent impressions against a highly photoluminescent background. In this case, it would appear that the Nile red component of the reagent partitions into the adhesive of the electrical tape, while Nile Blue A interacts preferentially with the fingermark residue. When viewed under Polilight illumination, improved contrast between the fingermarks and the background was achieved compared to viewing under white light. Further work is required to determine whether this phenomenon is isolated to the type of adhesive involved here or whether this may be more widely applicable to adhesive tape in general.

The combination of Nile blue A and Nile red in a single aqueous solution enables fingermark detection on a wider variety of surface types than is possible with Nile red alone. In addition Nile blue $\mathrm{A}$ is significantly cheaper than Nile red. The cost of Nile blue A used in this work to make $1 \mathrm{~L}$ of working solution is $\mathrm{A} \$ 0.30$, as opposed to Nile red where the cost is
A \$30. The low toxicity, low cost and simplicity of the reagent creates additional potential for operational use in developing countries or in personnel training. Further investigations into the applicability of Nile blue to a wider range of substrate types, reagent sensitivity and efficacy on natural (uncharged) and older fingermarks are currently underway.

The authors wish to thank Dr. Alan Payne (Curtin University) for assistance with the reaction mechanism, Prof. Claude Roux and Dr. Xanthe Spindler (University of Technology, Sydney) for providing access to unpublished reports and for useful discussions during the course of this work. The authors are also grateful to CWQRC (Perth, WA) for access to the HRMS instrumentation used to conduct part of this study. A.A. Frick is supported by an Australian Postgraduate Award. This study has been approved by the Curtin University Human Research Ethics Committee (Approval Number SMEC-07-13 and SMEC-47-13).

\section{Notes and references}

${ }^{a}$ Department of Chemistry, Curtin University, GPO Box U1987, Perth, Western Australia 6845, Australia. Fax: +61 89266 2300;Tel: +61 89266 2484; E-mail: S.Lewis@curtin.edu.au

${ }^{b}$ Australian Federal Police Forensics, GPO Box 401, Canberra ACT 2601

$\dagger$ To avoid confusion, the term 'Nile blue' is used in this paper specifically in reference to the aqueous reagent. The dye compound itself is referred to as 'Nile blue A'.

Electronic Supplementary Information (ESI) available: Fluorescence spectra, high resolution mass spectrometry (HRMS) data. See DOI: $10.1039 / \mathrm{c} 000000 \mathrm{x} /$

1. C. Champod, C. Lennard, P. Margot and M. Stoilovic, Fingerprints and Other Ridge Skin Impressions, CRC Press, Boca Raton, 2004.

2. R. Jelly, S. W. Lewis, C. Lennard, K. F. Lim and J. Almog, Chemical Communications, 2008, 3513-3515.

3. M. Sametband, I. Schweky, U. Banin, D. Mandler and J. Almog, Chemical Communications, 2007, 1142-1144.

4. A. M. Boddis and D. A. Russell, Analytical Methods, 2012, 4, 637641.

5. P. F. Kelly, R. S. P. King and R. J. Mortimer, Chemical Communications, 2008, 6111-6113.

6. A. Beaudoin, Journal of Forensic Identification, 2004, 54, 413-421.

7. A. Girod, R. Ramotowski and C. Weyermann, Forensic Science International, 2012.

8. R. Jelly, E. L. T. Patton, C. Lennard, S. W. Lewis and K. F. Lim, Analytica Chimica Acta, 2009, 652, 128-142.

9. J. Almog, in Advances in Fingerprint Technology, eds. H. Lee and R. Gaensslen, CRC Press, Boca Raton, 2001, pp. 177-209.

10. J. Salama, S. Aumeer-Donovan, C. Lennard and C. Roux, Journal of Forensic Identification, 2008, 58, 203-237.

11. A. Cantu and A. Johnson, in Advances in Fingerprint Technology, eds. H. Lee and R. Gaensslen, CRC Press, Boca Raton, 2001, pp. 241-274.

12. A. A. Cantu, Forensic Science Review, 2000, 13, 29-64.

13. HOSDB Source Book, Home Office Scientific Development Branch, Sandridge, UK, 2011. 
14. K. Braasch, M. de la Hunty, J. Deppe, X. Spindler, A. A. Cantu, P. Maynard, C. Lennard and C. Roux, Forensic Science International, 2013, 230, 74-80.

15. M. de la Hunty, Honours Thesis, University of Technology, Sydney, 2012.

16. A. J. Cain, Quarterly Journal of Microscopical Science, 1947, 88, 383-392.

17. J. D. Bancroft and H. C. Cook, Manual of Histological Techniques and their Diagnostic Application, Churchill Livingstone, Edinburgh, 1994.

18. J. L. Smith, Journal of Pathology and Bacteriology, 1908, 12, 1-4.

19. M. G. Dunnigan, Stain Technology, 1968, 43, 249-256.

20. A. G. Ostle and J. G. Holt, Applied and Environmental Microbiology, 1982, 44, 238-241.

21. J. L. Smith, Journal of Pathology and Bacteriology, 1911, 15, 53-55.

22. M. Canente, M. J. Hazen and J. C. Stockert, Acta Histochemica et Cytochemica, 1983, 16, 286-288.

23. P. Greenspan, E. P. Mayer and S. D. Fowler, Journal of Cell Biology, 1985, 100, 965-973.

24. S. D. Fowler and P. Greenspan, Journal of Histochemistry and Cytochemistry, 1985, 33, 833-836.

25. E. Bonilla and A. Prelle, Journal of Histochemistry and Cytochemistry, 1987, 35, 619-621.

26. E. Menzel and K. Fox, Journal of Forensic Sciences, 1980, 25, 150153.

27. B. K. Chesher, J. M. Stone and W. F. Rowe, Forensic Science International, 1992, 57, 163-168.

28. A. Castello, M. Alvarez-Segui and F. Verdu, Coloration Technology, 2004, 120, 184-187.

29. J. Jose and K. Burgess, Tetrahedron, 2006, 62, 11021-11037.

30. P. Greenspan and S. D. Fowler, Journal of Lipid Research, 1985, 26, 781-789. 